\title{
Trypanosoma cruzi benznidazole susceptibility in vitro does not predict the therapeutic outcome of human Chagas disease
}

\author{
Margoth Moreno', Daniella A D'ávila², Marcelo N Silva', Lúcia MC Galvãoº, \\ Andrea M Macedo ${ }^{4}$, Egler Chiari ${ }^{2}$, Eliane D Gontijo ${ }^{5}$, Bianca Zingales ${ }^{1 /+}$
}

'Departamento de Bioquímica, Instituto de Química, Universidade de São Paulo, Av. Prof. Lineu Prestes 748, 05508-000 São Paulo, SP, Brasil ${ }^{2}$ Departamento de Parasitologia ${ }^{4}$ Departamento de Bioquímica e Imunologia, Instituto de Ciências Biológicas ${ }^{5}$ Departamento de Medicina Preventiva e Social, Faculdade de Medicina, Universidade Federal de Minas Gerais, Belo Horizonte, MG, Brasil ${ }^{3}$ Programas de

Pós-Graduação em Ciências da Saúde e Ciências Farmacêuticas, Universidade Federal do Rio Grande do Norte, Natal, RN, Brasil

Therapeutic failure of benznidazole (BZ) is widely documented in Chagas disease and has been primarily associated with variations in the drug susceptibility of Trypanosoma cruzi strains. In humans, therapeutic success has been assessed by the negativation of anti-T. cruzi antibodies, a process that may take up to 10 years. A protocol for early screening of the drug resistance of infective strains would be valuable for orienting physicians towards alternative therapies, with a combination of existing drugs or new anti-T. cruzi agents. We developed a procedure that couples the isolation of parasites by haemoculture with quantification of BZ susceptibility in the resultant epimastigote forms. BZ activity was standardized with reference strains, which showed $I C_{50}$ to BZ between 7.6-32 $\mu M$. The assay was then applied to isolates from seven chronic patients prior to administration of $B Z$ therapy. The $I C_{50}$ of the strains varied from 15.6 $\pm 3-51.4 \pm 1 \mu \mathrm{M}$. Comparison of BZ susceptibility of the pre-treatment isolates of patients considered cured by several criteria and of non-cured patients indicates that the assay does not predict therapeutic outcome. A two-fold increase in BZ resistance in the post-treatment isolates of two patients was verified. Based on the profile of nine microsatellite loci, sub-population selection in non-cured patients was ruled out.

Key words: Chagas disease - benznidazole treatment - drug susceptibility - microsatellites

Human Chagas disease is a neglected illness that affects 10-12 million individuals from nearly all countries of Latin America. Due to migrations, Chagas disease cases have been reported throughout the world. In Latin America, the transmission of the protozoan Trypanosoma cruzi, the causative agent of Chagas disease, has been steadily reduced through a series of multinational initiatives aimed at the elimination of domestic vectors in extensive areas, as well as screening of blood donors for $T$. cruzi infection (Schofield et al. 2006). Nevertheless, serious challenges remain for complete elimination of transmission, including the peculiar epidemiology of Chagas disease, limitations in the available specific chemotherapy and insufficient treatment coverage for individuals currently infected.

Chagas disease progresses through two successive stages: the acute phase, with patent parasitemia, and the chronic phase, characterized by sub-patent parasitemia and scarce tissue parasitism. The majority of chronic individuals are asymptomatic (indeterminate form), whereas up to $30-40 \%$ of patients develop chronic cardiomyopathy or gastrointestinal disorders. While Chagas disease pathology is poorly understood, accumulating

Financial support: FAPESP, CNPq/MS-SCTIE-DECIT

MV and DADA were recipients of graduation fellowships from CNPq. + Corresponding author: zingales@iq.usp.br

Received 28 June 2010

Accepted 26 August 2010 evidence indicates that parasite persistence within the target organs, in concert with an unbalanced immune response, plays a central role in the development of pathology in both the acute and chronic phases (WHO 2002). Accordingly, the prevailing opinion is that Chagas disease should be treated with anti-parasitic compounds (Gontijo et al. 1999, WHO 2002).

Two nitro-heterocyclic compounds have been used for the specific treatment of $T$. cruzi infection: nifurtimox (NF) (launched by Bayer in 1967, Lampit ${ }^{\circledR}$ ) and benznidazole (BZ) (launched by Roche in 1972, Rochagan ${ }^{\circledR}$ and Radanil $^{\mathbb{B}}$ ) (Coura \& de Castro 2002). In patients, the two compounds require long courses of treatment and exhibit variable efficacy and undesirable side effects. Numerous clinical trials have reported up to $80 \%$ parasitological cure in the acute phase (Bahia-Oliveira et al. 2000) and $60-70 \%$ cure in recently developed chronic phase disease in children up to 14 years of age (de Andrade et al. 1996, Sosa-Estani et al. 1998, 2009, Yun et al. 2009). The major limitation on the use of both $\mathrm{BZ}$ and NF is low anti-parasitic activity in the chronic phase, with only $5-20 \%$ of patients considered cured, as assessed by 20 years or more follow-up (Cançado 2002, Dias 2006). On the other hand, BZ treatment in this phase yields a better prognosis for the clinical evolution of chagasic cardiomyopathies (Viotti et al. 2006, Sosa-Estani et al. 2009).

One of the priorities in Chagas disease research should be to produce new drugs, providing a shorter treatment course with fewer side effects and to devise paediatric formulations for these drugs. Ergosterol biosynthesis inhibitors are currently the most advanced candidates for new anti-T. cruzi agents, as they have been 
shown to have curative activity in chronic infections in mice and to be active against NF and BZ-resistant $T$. cruzi strains (Urbina 2009). Ergosterol biosynthesis inhibitors are poised for clinical trials in Chagas disease patients in the short term. An expert committee has also recommended that combination therapy using existing and/or new drugs should be employed to avoid drug resistance (Report of the Disease Reference Group of TDR on Chagas disease, Leishmaniasis and Human African Trypanosomiasis, personal communication).

The reasons for the marked differences in efficacy for the nitroderivatives in the acute and chronic stages of Chagas disease are not known (Cançado 2002). In addition, geographic differences in therapeutic outcome were reported, indicating that indices of cure can be detected earlier in Central America and northern countries of South America than in Southern Cone countries (Rassi \& Luquetti 1992, Yun et al. 2009). Such differences may be explained by a number of reasons. One primary explanation may be the presence of different parasite lineages in different geographic regions, with $T$. cruzi I predominating in Central America and T. cruzi II in South America (Carranza et al. 2009 and cited references). In fact, variations in drug susceptibility among T. cruzi strains have been documented widely in in vitro and in vivo studies (Filardi \& Brener 1987, Murta et al. 1998, Toledo et al. 2003, Villarreal et al. 2004). Another factor to consider is the time between vector control activity and drug treatment because cases (mostly asymptomatic) treated closer to the time of the acute phase of the disease might account for more rapid cure. Finally, differences in immune response among populations may also play a role (Yun et al. 2009).

A serious problem related to the treatment of Chagas disease is the unsatisfactory evaluation of therapy efficacy and diagnosis of cure. Currently, successful treatment is assessed by the disappearance of anti-T. cruzi antibodies (seroconversion), while therapeutic failure is assigned by the persistence of the parasite. Regrettably, serological markers may take up to 10 years to disappear and parasitological tests by haemoculture or xenodiagnosis have limited sensitivity (Gontijo et al. 1999). An upcoming polymerase chain reaction (PCR)-based assay is a promising tool in the evaluation of parasitological cure, but it still presents limitations (Britto 2009). Therefore, the lack of a better marker for indicating parasitological cure is a major impediment to advances in the treatment and development of more effective drugs for Chagas disease.

Contrary to bacterial infections, in which laboratory assays to measure antibiotic susceptibility are well established, a procedure to evaluate BZ susceptibility of $T$. cruzi parasites isolated from humans has not been standardized. The early diagnosis of drug resistance would improve the clinical management of Chagas disease, dictating alternative therapies with a combination of existing drugs or new anti-T. cruzi agents. In this study, we have developed a methodology to quantify BZ susceptibility in haemoculture-derived isolates from patients in the chronic phase of Chagas disease. The procedure was applied to parasites obtained before and after BZ treatment. Comparison of the in vitro BZ resistance of the pre-treatment parasites from patients considered cured and from those experiencing therapeutic failure showed no correlation with therapeutic outcome.

\section{PATIENTS, MATERIALS AND METHODS}

Parasite isolates and cultivation - Human isolates were obtained by haemoculture as described by Chiari et al. (1989) with some modifications. Briefly, $30 \mathrm{~mL}$ venous blood was collected in heparinized tubes and red blood cells were separated from the plasma by centrifugation $\left(300 \mathrm{~g}\right.$ for $\left.10 \mathrm{~min}, 4^{\circ} \mathrm{C}\right)$. The plasma supernatant was centrifuged $\left(900 \mathrm{~g}\right.$ for $20 \mathrm{~min}, 4^{\circ} \mathrm{C}$ ) and $3 \mathrm{~mL}$ liver infusion-tryptose (LIT)-10\% foetal calf serum (FCS) medium was added to the pellet. The packed red blood cells were further washed and resuspended in $6 \mathrm{~mL}$ LIT-FCS. The samples were pooled, distributed into plastic tubes (Falcon) containing $3 \mathrm{~mL}$ LIT-FCS each and maintained at $28^{\circ} \mathrm{C}$. In order to minimize parasite selection, LIT-FCS medium was added every two days to each culture for a maximum of eight weeks. Parasites were cryopreserved in liquid nitrogen. The characteristics of $T$. cruzi laboratory strains employed in this study are summarized in Table I. The recently proposed nomenclature for the strains is used, where discrete typing units (DTU) are defined as sets of stocks that are genetically more related to each other than to any other stock and that are identifiable by common genetic, molecular or immunological markers (Zingales et al. 2009).

Molecular typing of patient isolates - For DNA extraction, cryopreserved stocks were thawed and cultured in LIT-FCS medium. Epimastigotes were washed three times in phosphate-buffered saline by centrifugation $\left(2,000 \mathrm{~g}\right.$ for $\left.15 \mathrm{~min}, 4^{\circ} \mathrm{C}\right)$. Total parasite DNA was obtained as described (Macedo et al. 1992). T. cruzi genotyping was performed by amplifying nine microsatellite loci: SCLE10, SCLE11, MCLE01, MCLF10 and MCLG10 (Oliveira et al. 1998) and TcTAT20, TcAAT8, TcATT14 and TcAAAT6 (Valadares et al. 2007). Amplification of microsatellites by PCR was achieved as previously described (Oliveira et al. 1998, Valadares et al. 2007). The microsatellite allele sizes were determined using the Allelelocator software (GE Healthcare) after running 1-3 $\mu \mathrm{L}$ of PCR fluorescent amplicons in a 6\% denaturing polyacrylamide gel on an ALF sequencer (GE Healthcare, Milwaukee, Wisconsin, USA) in comparison to standard size DNA fragments of 50-500 bp.

Patients and treatment scheme - Since 1997, one of us (EDG), in conjunction with researchers of the Clinics Hospital of the Federal University of Minas Gerais (UFMG), has been conducting a prospective study to test the hypothesis that BZ treatment can impact the evolution of the disease, preventing or retarding the development of defined clinical forms. Patients enrolled in the present study were recruited in the city of Belo Horizonte, $\mathrm{MG}$, and were randomly assigned $\mathrm{BZ}(5 \mathrm{mg} / \mathrm{kg}$ daily, distributed in 2 oral intakes, for 60 days). Further details on the prospective study will be published elsewhere. The study protocol was ethically and technically reviewed and approved by the Ethical Committee of UFMG. Signed informed consent was obtained from the 
participants. Two conventional serological tests (indirect immunofluorescence and enzyme linked immunosorbent assay), antibody-dependent complement-mediated lysis, haemoculture, PCR targeted to kDNA in blood samples (Galvão et al. 1993, Meira et al. 2002) and clinical evaluations (electrocardiograms, echocardiograms and chest X-rays) were performed before treatment and at least biannually after treatment. In the present study, only seven patients of the original cohort were included. Treatment was started after haemocultures produced positive scores. All the patients completed treatment. During follow-up, individuals lived in an urban area and did not travel to endemic areas. The characteristics of the patients are summarized in Table II.

Assay to evaluate BZ susceptibility - The assay was performed in 24-well, flat-bottom tissue culture plates
(Falcon) in $1 \mathrm{~mL}$ LIT-FCS medium. Different amounts of BZ from a $50 \mathrm{mM}$ stock solution in dimethyl sulfoxide (DMSO) were added to each well. Exponentially growing epimastigotes $\left(10^{7}\right.$ parasites $\left./ \mathrm{mL}\right)$ were incubated with the compound for $72 \mathrm{~h}$ at $28^{\circ} \mathrm{C}$. After this period, the number of living parasites was counted in a Neubauer chamber. Drug activity was determined by calculating the percentage of growth inhibition in the treated samples against the control in the absence of BZ. Three independent assays with duplicates in each assay were performed on separate occasions.

Statistical analysis - For calculation of $\mathrm{IC}_{50}$, corresponding to the drug concentration that inhibited parasite growth by $50 \%$, the data were treated with SigmaPlot (version 10) software, employing the sigmoidal equation four-parameter logistic.

TABLE I

Characteristics of Trypanosoma cruzi laboratory strains

\begin{tabular}{|c|c|c|c|c|}
\hline Strain & $\begin{array}{l}\text { Geographical } \\
\text { origin }\end{array}$ & $\begin{array}{c}\text { Host } \\
\text { (phase of disease/vector) }\end{array}$ & $\mathrm{DTU}^{b}$ & $\begin{array}{c}\mathrm{IC}_{50} \mathrm{BZ}(\mu \mathrm{M}) \\
(\text { mean } \pm \mathrm{SD})\end{array}$ \\
\hline 115 & Minas Gerais (BR) & Human (chronic) & $\mathrm{V}$ & $7.6 \pm 3.6$ \\
\hline Berenice $62^{a}$ & Minas Gerais & Human (chronic) & II & $12.8 \pm 4.9$ \\
\hline CL Brener $^{a}$ & Rio Grande do Sul (BR) & Triatoma infestans & VI & $13.6 \pm 4.4$ \\
\hline $\mathrm{Y}^{a}$ & São Paulo (BR) & Human (acute) & II & $16.3 \pm 2.0$ \\
\hline Berenice 78 & Minas Gerais & Human (chronic) & II & $15.8 \pm 3.8$ \\
\hline B147 & Minas Gerais & Human (chronic) & ND & $25.5 \pm 3.3$ \\
\hline Colombiana $^{a}$ & Colombia & Human (chronic) & I & $25.4 \pm 2.7$ \\
\hline Esmeraldo cl3 & Bahia (BR) & Human (acute) & II & $26.7 \pm 0.3$ \\
\hline Silvio X10 ${ }^{a}$ & Pará (BR) & Human (acute) & I & $26.1 \pm 2.5$ \\
\hline $\mathrm{VL}^{\prime} 0^{a}$ & Minas Gerais & Human (chronic) & II & $27.3 \pm 2.0$ \\
\hline SC2005 & Santa Catarina (BR) & Human (acute) & ND & $32.1 \pm 5.9$ \\
\hline $\mathrm{YuYu}^{a}$ & Minas Gerais & T. infestans & I & $32.0 \pm 0.2$ \\
\hline
\end{tabular}

$a$ : benznidazole (BZ) susceptibility was determined in experimentally infected mice (Filardi \& Brener 1987); $b$ : discrete typing units (DTU) groups classified according to Zingales et al. (2009); BR: Brazil; ND: not determined; SD: standard deviation.

TABLE II

Patients' profile

\begin{tabular}{|c|c|c|c|c|}
\hline $\begin{array}{l}\text { Patient's } \\
\text { code }\end{array}$ & Gender & $\begin{array}{l}\text { Clinical } \\
\text { form }\end{array}$ & $\begin{array}{l}\text { Age }^{a} \\
\text { (years) }\end{array}$ & Status of the haemocultures after treatment ${ }^{b}$ \\
\hline 3 & $\mathrm{~F}$ & Indeterminate & 28 & $\begin{array}{c}(+) 6 \mathrm{mo} \\
(-) 16 \mathrm{mo} ; 31 \mathrm{mo} ; 71 \mathrm{mo} ; 92 \mathrm{mo}\end{array}$ \\
\hline 7 & $\mathrm{~F}$ & Indeterminate & 33 & (-) $7 \mathrm{mo} ; 52 \mathrm{mo} ; 66 \mathrm{mo} ; 95 \mathrm{mo} ; 102 \mathrm{mo}$ \\
\hline 12 & M & Indeterminate & 51 & $\begin{array}{l}\text { (+) } 29 \mathrm{mo} ; 56 \mathrm{mo} \\
\text { (-) } 18 \mathrm{mo} ; 38 \mathrm{mo} ; 42 \mathrm{mo}\end{array}$ \\
\hline 19 & M & Mild cardiac damage & 45 & $\begin{array}{c}\text { (+) } 22 \mathrm{mo} ; 47 \mathrm{mo} ; 67 \mathrm{mo} ; 93 \mathrm{mo} \\
(-) 112 \mathrm{mo}\end{array}$ \\
\hline 22 & $\mathrm{~F}$ & Indeterminate & 37 & (-) $7 \mathrm{mo} ; 18 \mathrm{mo} ; 35 \mathrm{mo} ; 56 \mathrm{mo} ; 72 \mathrm{mo} ; 84 \mathrm{mo}$ \\
\hline 36 & M & Indeterminate & 25 & (-) $4 \mathrm{mo} ; 56 \mathrm{mo} ; 91 \mathrm{mo}$ \\
\hline 50 & $\mathrm{~F}$ & Indeterminate & 39 & $\begin{array}{l}\text { (-) } 6 \mathrm{mo} ; 34 \mathrm{mo} ; 63 \mathrm{mo} \\
\text { (+) } 22 \mathrm{mo} ; 48 \mathrm{mo} ; 74 \mathrm{mo}\end{array}$ \\
\hline
\end{tabular}

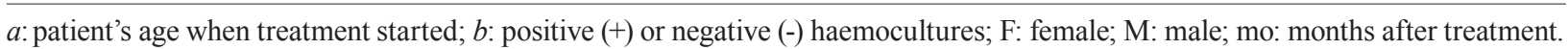




\section{RESULTS}

Standardization of the assay for screening BZ susceptibility - The in vitro assay was standardized with epimastigote forms, as this developmental stage is predominant in haemocultures obtained from infected individuals. The VL10 strain, classified as resistant to BZ (Filardi \& Brener 1987), was employed in initial tests and incubated for $72 \mathrm{~h}$ with eight BZ concentrations (1.2-480 $\mu \mathrm{M}$, serial dilutions 1:2) (data not shown). The $\mathrm{IC}_{50}$ value obtained from three separate assays with duplicates in each assay was $27.3 \pm 2 \mu \mathrm{M}$ (Table I). Because the stock solution of BZ was diluted in DMSO, we analyzed the effect of different concentrations of this solvent on the viability of VL10 epimastigotes. Final DMSO concentrations of $0.031-4 \%$ had no significant effect on parasite growth (data not shown).

To validate the assay, susceptibility to BZ was assessed for 11 additional T. cruzi laboratory strains (Table I). The $\mathrm{IC}_{50}$ to $\mathrm{BZ}$ varied from 7.6 $\pm 3.6-32.1 \pm 5.9 \mu \mathrm{M}$. The BZ susceptibility of seven of the analyzed strains (indicated with an " $a$ " in Table I) had been previously determined in experimentally infected mice (Filardi \& Brener 1987). According to the authors, the strains were classified as susceptible (cure rates $>66 \%$ ), partially susceptible (cure rates between 33-66\%) and resistant (cure rates $<33 \%$ ). Two strains considered susceptible (Berenice 62 and CL) and one strain considered partially susceptible (Y) to $\mathrm{BZ}$ had $\mathrm{IC}_{50}$ values between 12.8 $\pm 4.9-16.3 \pm 2 \mu \mathrm{M}$ in our assay (Table I). Three strains considered resistant (Colombiana, VL10 and YuYu) had $\mathrm{IC}_{50}$ between $25.4 \pm 2.7$ and $32.0 \pm 0.2 \mu \mathrm{M}$. These observations suggest a correlation between in vitro BZ susceptibility and the treatment outcome reported in the experimental model. A possible exception is the Silvio X10 strain, considered susceptible to BZ (Filardi \& Brener 1987), but which showed a high $\mathrm{IC}_{50}$ in our assay (Table I). Interestingly, the Silvio X10 strain was found to be resistant to NF in the experimental model, at variance with the great majority of the stocks that were either sensitive or resistant to both nitro-heterocyclic compounds (Filardi \& Brener 1987).

Based on agreement between in vivo and in vitro BZ activity, we divided the laboratory strains into two groups and calculated the mean \pm standard deviation (SD) of each group: group 1, susceptible $\left(\mathrm{n}=5 ; \mathrm{IC}_{50} 13.3 \pm 4.5 \mu \mathrm{M}\right)$, and group 2, resistant $\left(\mathrm{n}=7 ; \mathrm{IC}_{50} 28 \pm 4.4 \mu \mathrm{M}\right)$.

To verify the stability of the BZ susceptibility phenotype, we determined the $\mathrm{IC}_{50}$ of two strains (115 and $\mathrm{YuYu}$ ) kept for four months via weekly sub-culture in LIT-FCS medium. The $\mathrm{IC}_{50}$ values determined monthly did not show any considerable variation, falling within the limits of the SD (data not shown).

BZ susceptibility of T. cruzi clinical isolates - In haemocultures derived from $30 \mathrm{~mL}$ blood, a suitable epimastigote density for the in vitro assay was achieved after approximately 60 days. The test for BZ susceptibility was applied to parasites obtained from seven chronic patients (4 females and 3 males), between 25-51 years of age (Table II). Six patients presented the indeterminate form of Chagas disease and one patient presented mild cardiac damage. $\mathrm{IC}_{50}$ values ranging from $15-50 \mu \mathrm{M}$ were observed for the seven isolates obtained before initiation of treatment (Figure, Table III). The patients were submitted to BZ therapy and, at different times after treatment, haemocultures were performed and the presence of parasites scored (Table II). The titre of anti-T. cruzi antibodies, antibody-dependent complement-mediated lysis and PCR targeted to kDNA were also assessed (data to be presented elsewhere). All of the haemocultures derived from patients 7, 22 and 36 were negative for parasites, as were the PCR assays (data not shown). Negativation of anti-T. cruzi antibodies in these patients was observed after 8.5 (patient 7), seven (patient 22) and

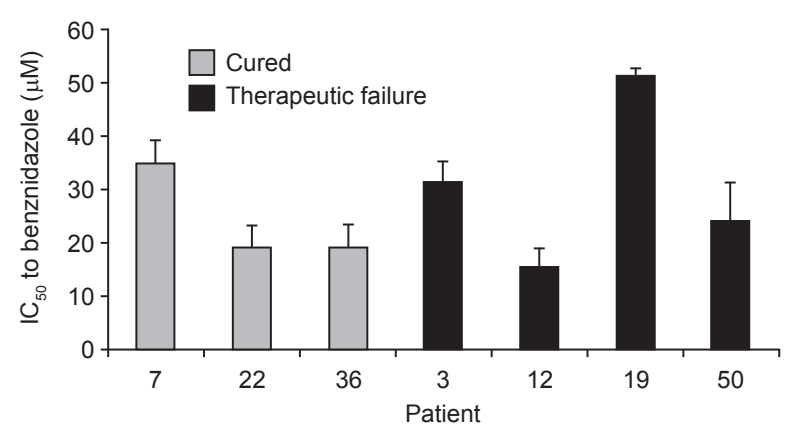

Susceptibility to benznidazole (BZ) in clinical Trypanosoma cruzi isolates. Susceptibility to BZ was quantified in epimastigotes derived from haemocultures of seven chagasic patients before chemotherapy. Based on the accepted criteria, three patients were considered cured.

TABLE III

Susceptibility to benznidazole (BZ)

of Trypanosoma cruzi human isolates

$\mathrm{IC}_{50} \mathrm{BZ}(\mu \mathrm{M})$

(mean \pm standard deviation)

Isolate $^{a}$ Before After treatment

(code) treatment (period in which the isolate was obtained)

\begin{tabular}{lcc}
\hline 3 & $31.5 \pm 4.0$ & $10.1 \pm 1.8$ \\
& & $(6 \mathrm{mo})$ \\
7 & $35.0 \pm 4.1$ & - \\
12 & $15.6 \pm 3.2$ & $37.5 \pm 7.0$ \\
& & $(1 \mathrm{mo})$ \\
19 & $51.4 \pm 1.3$ & $43.45 \pm 3.5$ \\
& & $(47 \mathrm{mo})$ \\
& & $48.9 \pm 5.0$ \\
22 & $19.2 \pm 4.1$ & - \\
36 & $19.4 \pm 4.2$ & - \\
50 & $24.4 \pm 7.0$ & $55.2 \pm 3.5$ \\
& & $(48 \mathrm{mo})$
\end{tabular}

$a$ : the isolates are named with the same patient's code from whom they derived (Table II); mo: months after treatment. 
7.6 (patient 36) years of treatment. According to these criteria, the patients were considered cured (Gontijo et al. 1999). The $\mathrm{IC}_{50}$ values of the epimastigotes of these patients were $19 \pm 4 \mu \mathrm{M}$ (patients 22 and 36) and $35 \pm 4 \mu \mathrm{M}$ (patient 7) (Table III). The $\mathrm{IC}_{50}$ of the pre-treatment parasites derived from the non-cured patients $3,12,19$ and 50 varied from 15.6-51.4 $\mu \mathrm{M}$ (Table III). These data indicate that the $\mathrm{IC}_{50}$ values determined in our assay do not predict the outcome of $\mathrm{BZ}$ treatment. It is remarkable that the $\mathrm{IC}_{50}$ to $\mathrm{BZ}$ of the pre-treatment isolate of the non-cured patient $012(15.6 \pm 3.2 \mu \mathrm{M})$ is within the range of the $\mathrm{IC}_{50}$ values of the above-mentioned group 1 (susceptible strains), whereas the $\mathrm{IC}_{50}$ of the parasites of the putatively cured patient $7(35 \pm 4.1 \mu \mathrm{M})$ falls into that of group 2 (resistant strains).

We also determined the BZ susceptibility of the epimastigotes derived from post-treatment parasites from the four non-cured patients (Table III). Comparison of the pre and post-treatment $\mathrm{IC}_{50}$ was notable (Table III): the isolates of patient 19 had a conserved high $\mathrm{IC}_{50}$ value before $(51.4 \pm 1.3 \mu \mathrm{M})$ and after treatment $(43.45 \pm 3.5$ and $48.9 \pm 5.0 \mu \mathrm{M}$ ), whereas post-treatment isolates of patients 12 and 50 showed a two-fold increase in resistance to BZ as compared to pre-treatment isolates. On the other hand, the post-treatment isolate of patient 3 showed increased susceptibility to BZ (Table III).

Molecular typing of the isolates - In Chagas disease, the individual may be infected with more than one parasite population (Macedo et al. 2004). Contemplating the hypothesis that variation in the $\mathrm{IC}_{50}$ of the isolates obtained before and after treatment could be related to the selection of a particular parasite population, we proceeded to genotype parasites based on the analysis of nine polymorphic microsatellite loci containing di, tri and tetra-nucleotide repetition motifs (Table IV). Using this set of microsatellites, it was possible to differentiate pre-treatment parasite populations for all four evaluated patients. In fact, only the locus TcAAAT6 was monomorphic for the group of parasites under analysis. Inter- estingly, when examining pre and post-treatment isolates from a given patient, we concluded that the population was monoclonal and identical, as indicated by the presence of only one or two different alleles per locus. Accordingly, and within the sensitivity of the microsatellite assay, we ruled out parasite selection or re-infection during or after treatment.

\section{DISCUSSION}

The three stages of the T. cruzi life cycle have been used for in vitro drug screening. Although the intracellular amastigote model is considered the most consistent indicator of in vivo activity, a number of tests showed a strong correlation between the activity of compounds against epimastigote cultures and their activity in mice (Croft 1986, Urbina 2009). Nevertheless, differences of several orders of magnitude of the $\mathrm{IC}_{50}$ values of epimastigotes and amastigotes were reported.

Because the goal of this study was to develop a procedure to measure the BZ susceptibility of clinical isolates with the aim of predicting the response to treatment, rather than correlating BZ susceptibility of the epimastigotes with the treatment outcome, we standardized the assay with haemoculture-derived epimastigotes. We have not attempted to develop the assay using intracellular amastigotes because the process is time consuming and can lead to the selection of a particular parasite population. The amastigote model involves the differentiation of haemoculture-derived epimastigotes into metacyclic trypomastigotes in order to establish infection in mammalian cell monolayers. We have made an effort to obtain metacyclic trypomastigotes from the clinical isolates in differentiation media. The differentiation efficiency varied from $0-50 \%$ (data not shown) depending on the isolate. We have not used bloodstream trypomastigotes because their numbers are low in the chronic phase of Chagas disease.

Standardization of the assay to measure BZ susceptibility was performed with $T$. cruzi reference strains, which showed $\mathrm{IC}_{50}$ between 7.6-30 $\mu \mathrm{M}$. These values are

TABLE IV

Genetic characterization of Trypanosoma cruzi isolates of non-cured patients obtained before (BT) and after (AT) benznidazole treatment

\begin{tabular}{lcccccccc}
\hline & \multicolumn{7}{c}{ Allele sizes (in bp) of microsatellite loci } \\
\cline { 2 - 8 } $\begin{array}{l}\text { Isolate } \\
\text { (code) }\end{array}$
\end{tabular}

$a$ : see details in Table III; $b$ : 93 months after treatment. 
of the same order of magnitude of $\mathrm{IC}_{50}$ of epimastigotes in stocks belonging to different DTU (Villarreal et al. 2004). Some studies reported that DTU I isolates were more resistant to BZ than parasites of the other DTUs (Toledo et al. 2003, 2004), whereas others showed no correlation between in vitro drug susceptibility and $T$. cruzi groups (Murta et al. 1998, Villarreal et al. 2004). Our data support the latter conclusion. We observed that the $\mathrm{IC}_{50}$ value is a stable characteristic that is maintained during prolonged epimastigote sub-culturing (up to 4 months). This observation agrees with previous reports showing that drug-resistant $T$. cruzi parasites maintain this phenotype after six months of sub-culturing without drug pressure (Nirdé et al. 1995).

The $\mathrm{IC}_{50}$ values to $\mathrm{BZ}$ of T. cruzi isolates derived from seven patients before initiation of treatment varied from 15.6 $\pm 3.2-51.4 \pm 1.3 \mu \mathrm{M}$. Comparison of the pre-treatment $\mathrm{IC}_{50}$ values of parasites from cured and non-cured individuals showed no correlation with therapeutic outcome. Because the diagnosis of cure of Chagas disease is unsatisfactory, the possibility exists that patients considered cured are in fact still infected. On the other hand, this hypothesis does not invalidate the conclusion that the $\mathrm{IC}_{50}$ determined in vitro is not predictive of therapeutic success.

Comparison of the BZ activity in pre and post-treatment isolates showed a 2-fold increase in drug resistance in the post-treatment parasites of two patients. At least two hypotheses could explain this observation: (i) the selection of a more resistant parasite population already present in the original infecting strain or (ii) the induction of resistance by the selective pressure of the drug during therapy. Both hypotheses find support in the literature (Nirdé et al. 1995, Veloso et al. 2001, Villarreal et al. 2005, Wilkinson et al. 2008). Due to the remarkable polymorphism of microsatellite markers, as few as four microsatellite loci is usually enough to differentiate any two $T$. cruzi populations, even those that are genetically closely related (Oliveira et al. 1998, Macedo et al. 2001). Based on the profile of nine microsatellite loci, we ruled out any parasite selection process that may have occurred during or after BZ treatment. On the other hand, global genetic analysis based on these markers does not allow the identification either of specific mutations or of the amplification of genes which could promote increased resistance to BZ. Microsatellite markers also excluded sub-population selection of the post-treatment isolate that displayed increased BZ susceptibility. Variations in the activity of the drug in parasites recovered after treatment deserve future investigation.

In the present study, our conclusion that this in vitro assay does not allow the prediction of therapeutic outcome is intriguing and challenging. The most obvious explanation would be that the epimastigote is not the infective stage and its susceptibility to BZ does not reflect the susceptibility of other stages (trypomastigotes and amastigotes) encountered in the human host. On the other hand, our data support the proposition that therapeutic success seems to depend on the interplay among parasite susceptibility to the trypanocidal drug, drug access and accumulation into different environ- ments (plasma levels and also targeted tissues) and the host immune response. These parameters warrant more in-depth investigation for both the understanding of BZ trypanocidal activity and the rational development of new anti-Chagas disease compounds.

\section{REFERENCES}

Bahia-Oliveira LM, Gomes JA, Cançado JR, Ferrari TC, Lemos EM, Luz ZM, Moreira MC, Gazzinelli G, Correa-Oliveira R 2000. Immunological and clinical evaluation of chagasic patients subjected to chemotherapy during the acute phase of Trypanosoma cruzi infection 14-30 years ago. J Infect Dis 182: 634-638.

Britto CC 2009. Usefulness of PCR-based assays to assess drug efficacy in Chagas disease chemotherapy: value and limitations. Mem Inst Oswaldo Cruz 104 (Suppl. I): 122-135.

Cançado JR 2002. Long term evaluation of etiological treatment of Chagas disease with benznidazole. Rev Inst Med Trop Sao Paulo 44: 29-37.

Carranza JC, Valadares HM, D’Avila DA, Baptista RP, Moreno M, Galvão LM, Chiari E, Sturm NR, Gontijo ED, Macedo AM, Zingales B 2009. Trypanosoma cruzi maxicircle heterogeneity in Chagas disease patients from Brazil. Int J Parasitol 39: 963-973.

Chiari E, Dias JC, Lana M, Chiari CA 1989. Hemocultures for the parasitological diagnosis of human chronic Chagas' disease. Rev Soc Bras Med Trop 22: 19-23.

Coura JR, de Castro SL 2002. A critical review on Chagas disease chemotherapy. Mem Inst Oswaldo Cruz 97: 3-24.

Croft SL 1986. In vitro screens in the experimental chemotherapy of leishmaniasis and trypanosomiasis. Parasitol Today 2: 64-69.

de Andrade AL, Zicker F, de Oliveira RM, Almeida Silva S, Luquetti A, Travassos LR, Almeida IC, de Andrade SS, de Andrade JG, Martelli CM 1996. Randomised trial of efficacy of benznidazole in treatment of early Trypanosoma cruzi infection. Lancet 348: 1407-1413.

Dias JCP 2006. The treatment of Chagas disease (South American trypanosomiasis). Ann Int Med 144: 772-774.

Filardi LS, Brener Z 1987. Susceptibility and natural resistance of Trypanosoma cruzi strains to drugs used clinically in Chagas disease. Trans R Soc Trop Med Hyg 81: 755-759.

Galvão LM, Nunes RM, Cançado JR, Brener Z, Krettli AU 1993. Lytic antibody titre as a means of assessing cure after treatment of Chagas disease: a 10-years follow-up study. Trans $R$ Soc Trop Med Hyg 87: 220-223.

Gontijo ED, Galvão LMC, Eloi-Santos S 1999. Chagas disease: criteria of cure and prognosis. Mem Inst Oswaldo Cruz 94 (Suppl. I): $357-362$.

Macedo AM, Machado CR, Oliveira RP, Pena SDJ 2004. Trypanosoma cruzi: genetic structure of populations and relevance of genetic variability to the pathogenesis of Chagas disease. Mem Inst Oswaldo Cruz 99: 1-12.

Macedo AM, Martins MS, Chiari E, Pena SD 1992. DNA fingerprinting of Trypanosoma cruzi: a new tool for characterization of strains and clones. Mol Biochem Parasitol 55: 147-153.

Macedo AM, Pimenta JR, de Aguiar RS, Melo AI, Chiari E, Zingales B, Pena SD, Oliveira RP 2001. Usefulness of microsatellite typing in population genetic studies of Trypanosoma cruzi. Mem Inst Oswaldo Cruz 96: 407-413.

Meira WS, Galvão LM, Gontijo ED, Machado-Coelho GL, Norris KA, Chiari E 2002. Trypanosoma cruzi recombinant complement regulatory protein: a novel antigen for use in an enzyme- 
linked immunosorbent assay for diagnosis of Chagas' disease. J Clin Microbiol 40: 3735-3740.

Murta SM, Gazzinelli RT, Brener Z, Romanha AJ 1998. Molecular characterization of susceptible and naturally resistant strains of Trypanosoma cruzi to benznidazole and nifurtimox. Mol Biochem Parasitol 93: 203-214.

Nirdé P, Larroque C, Barnabé C 1995. Drug-resistant epimastigotes of Trypanosoma cruzi and persistence of this phenotype after differentiation into amastigotes. CR Acad Sci III 318: 1239-1244.

Oliveira RP, Broude NE, Macedo AM, Cantor CR, Smith CL, Pena SD 1998. Probing the genetic population structure of Trypanosoma cruzi with polymorphic microsatellites. Proc Natl Acad Sci USA 95: 3776-3780.

Rassi A, Luquetti AO 1992. Therapy of Chagas disease. In S Wendel, Z Brener, ME Camargo, A Rassi (ed.), Chagas disease (American trypanosomiasis): its impact on transfusion and clinical medicine, ISBT Brazil'92, São Paulo, p. 237-247.

Schofield CJ, Jannin J, Salvatella R 2006. The future of Chagas disease control. Trends Parasitol 22: 583-588.

Sosa-Estani S, Segura EL, Ruiz AM, Velazquez E, Porcel BM, Yampotis C 1998. Efficacy of chemotherapy with benznidazole in children in the indeterminate phase of Chagas disease. Am J Trop Med Hyg 59: 526-529.

Sosa-Estani S, Viotti R, Segura EL 2009. Therapy, diagnosis and prognosis of chronic Chagas disease: insight gained in Argentina. Mem Inst Oswaldo Cruz 104 (Suppl. I): 167-180.

Toledo MJO, Bahia MT, Carneiro CM, Martins-Filho OA, Tibayrenc M, Barnabé C, Tafuri WL, de Lana M 2003. Chemotherapy with benznidazole and itraconazole for mice infected with different Trypanosoma cruzi clonal genotypes. Antimicrob Agents Chemother 47: 223-230.

Toledo MJO, Tafuri WL, Bahia MT, Tibayrenc M, Lana M 2004. Genetic diversity and drug resistance in Trypanosoma cruzi, the agent of Chagas disease. Res Adv Antimicrob Agents Chemother 4: 11-22.

Urbina JA 2009. Ergosterol biosynthesis and drug development for Chagas disease. Mem Inst Oswaldo Cruz 104 (Suppl. I): 311-318.
Valadares HM, Pimenta JR, de Freitas JM, Duffy T, Bartholomeu DC, Oliveira R de P, Chiari E, Moreira M da C, Filho GB, Schijman AG, Franco GR, Machado CR, Pena SD, Macedo AM 2007. Genetic profiling of Trypanosoma cruzi directly in infected tissues using nested PCR of polymorphic microsatellites. Int J Parasitol 38: 839-850.

Veloso VM, Carneiro CM, Toledo MJO, Lana M, Chiari E, Tafuri WL, Bahia MT 2001. Variation in susceptibility to benznidazole in isolates derived from Trypanosoma cruzi parental strains. Mem Inst Oswaldo Cruz 96: 1005-1011.

Villarreal D, Barnabé C, Sereno D, Tibayrenc M 2004. Lack of correlation between in vitro susceptibility to benznidazole and phylogenetic diversity of Trypanosoma cruzi, the agent of Chagas disease. Exp Parasitol 108: 24-31.

Villarreal D, Nirdé P, Hide M, Barnabé C, Tibayrenc M 2005. Differential gene expression in benznidazole-resistant Trypanosoma cruzi parasites. Antimicrob Agents Chemother 49: 2701-2709.

Viotti R, Vigliano C, Lococo B, Bertocchi G, Petti M, Alvarez MG, Postan M, Armenti A 2006. Long-term cardiac outcomes of treating chronic Chagas disease with benznidazole versus no treatment: a nonrandomized trial. Ann Intern Med 144: 724-734.

WHO - World Health Organization. Expert Committee 2002. Control of Chagas disease, Technical Report Series 905, WHO, Geneva, 120 pp.

Wilkinson SR, Taylor MC, Horn D, Kelly JM, Cheeseman I 2008. A mechanism for cross-resistance to nifurtimox and benznidazole in trypanosomes. Proc Natl Acad Sci USA 105: 5022-5027.

Yun O, Lima MA, Ellman T, Chambi W, Castillo S, Flevaud L, Roddy P, Parreño F, Albajar Viñas P, Palma PP 2009. Feasibility, drug safety, and effectiveness of etiological treatment programs for Chagas disease in Honduras, Guatemala, and Bolivia: 10-year experience of Médecins sans Frontières. PLoS Negl Trop Dis 3: e488.

Zingales B, Andrade SG, Briones MRS, Campbell DA, Chiari E, Fernandes O, Guhl F, Lages-Silva E, Macedo AM, Machado CR, Miles MA, Romanha AJ, Sturm NR, Tibayrenc M, Schijman AJ 2009. A new consensus for Trypanosoma cruzi intraspecific nomenclature: second revision meeting recommends $\mathrm{TcI}$ to $\mathrm{TcVI}$. Mem Inst Oswaldo Cruz 104: 1051-1054. 